\title{
Potensi dan Performa Reproduksi Indukan Sapi Bali dalam Mendukung Usaha Pembiakan di Stasiun Lapang Sekolah Peternakan Rakyat
}

\author{
Potential and Reproductive Performance of Female Bali Cattle for Supporting Breeding Business at Field \\ Station of Sekolah Peternakan Rakyat \\ D. A. P. Sari ${ }^{1 *}$, Muladno ${ }^{1}, \&$ S. Said ${ }^{2}$ \\ ${ }^{1}$ Departemen Ilmu Produksi dan Teknologi Peternakan, Fakultas Peternakan, Institut Pertanian Bogor \\ ${ }^{2}$ Pusat Penelitian Bioteknologi, Lembaga Ilmu Pengetahuan Indonesia \\ *Email koresponden author: dinda ayups@apps.ipb.ac.id \\ (Received 24-04-2020; Revised 31-05-2020; Accepted 05-06-2020)
}

\begin{abstract}
Reproductive performance of female cattle is one of the important factors that need to be known in supporting the efficiency of beef cattle breeding programs so that the dam can produce calves every year. This study aimed to evaluate the potential and reproductive performance of female Bali cattle to preparing a baseline for cattle breeding production in SL-SPR Maju Bersama, Sungai Lilin District. Three hundred and thirty female Bali cattle owned by 247 farmers were measured and recorded based on their production and reproduction performance. Data were collected by interview and observation. Data were analyzed using statistical and descriptive methods. Reproductive performance obtained is the age first calving $1098 \pm 120$ days; calving interval 457,25 $\pm 8,75$ days; days open $109,25 \pm 8,57$ days and service per conception $5,46 \pm 0,42$. The average female cattle have a BCS value of $3(43 \%)$. The result showed that the breeding of Bali cattle at SL-SPR had sufficient potential, but it was necessary to improve performance. The basic data obtained can be used to start a breeding business to increase populations and improve the genetic quality of Bali cattle.
\end{abstract}

Keywords: Bali cattle, Sekolah Peternakan Rakyat, Reproductive performance

\section{ABSTRAK}

Performa reproduksi induk merupakan salah satu faktor penting yang perlu diketahui dalam menunjang efisiensi program pembiakan sapi potong agar induk dapat menghasilkan anak setiap tahun. Penelitian ini bertujuan untuk melihat potensi dan performa reproduksi indukan sapi Bali dalam rangka penyusunan baseline usaha pembiakan sapi Bali di SL-SPR Maju Bersama, Kecamatan Sungai Lilin. Induk sapi sebanyak 330 ekor milik 247 peternak digunakan untuk melihat performa reproduksi. Data diperoleh melalui pengamatan, wawancara dengan pemilik ternak dan inseminator. Seluruh data yang diperoleh dianalisa secara statistik dan deskriptif. Performa reproduksi yang diperoleh yaitu umur pertama beranak $1098 \pm 12,0$ hari; calving interval 457,25 $\pm 8,57$ hari dan days open $109,25 \pm 8,57$ hari dan service per conception 5,46 $\pm 0,42$ kali. Rata-rata induk memiliki nilai BCS 3 (43\%). Hasil penelitian menunjukkan pembiakan indukan sapi Bali di SL-SPR memiliki potensi yang cukup, akan tetapi perlu dilakukan perbaikan kinerja reproduksi. Baseline data yang diperoleh dapat digunakan untuk memulai usaha pembiakan dalam rangka pengembangan populasi dan peningkatan mutu genetik ternak sapi.

Kata kunci: Sapi Bali, Sekolah Peternakan Rakyat, Kinerja reproduksi

\section{PENDAHULUAN}

Produksi daging sapi dalam negeri lebih dari $90 \%$ berasal peternakan rakyat dengan sistem pemeliharaan tradisional dan kurang efisien. Adapun sistem pemeliharan sapi potong yang bersifat tradisional memiliki ciri diantaranya skala kepemilikan yang relatif kecil, rata-rata 1-3 ekor tiap peternak, penggunaan teknologi dan inovasi yang masih terbatas serta pemeliharaan yang seadanya, mulai dari aspek pemberian pakan, kontrol perkawinan dan manajemen kesehatan ternak (Mauludin et al. 2012). Kecilnya skala kepemilikan ternak di peternak rakyat disebabkan karena umumnya kegiatan beternak sebatas sebagai usaha sampingan dan ternak dijadikan tabungan yang sewaktu-waktu butuh biaya, akan dijual tanpa 
menerapkan standar harga jual. Terjadinya seleksi negatif akibat penjualan ternak yang memiliki performa baik menyebabkan produktivitas ternak di peternak rakyat mengalami penurunan.

Strategi yang dapat dilakukan dalam rangka perbaikan dan pengembangan peternakan sapi potong di peternak rakyat adalah melalui perbaikan sistem produksi yang telah ada berbasis kelembagaan kelompok ternak (Sodiq dan Hidayat 2014). Terhimpunnya peternak dalam sebuah kelompok sangat penting diantaranya sebagai media untuk transfer teknologi dan informasi yang efektif serta sebagai wadah untuk menjalin kerjasama dengan kemitraan dalam rangka menunjang bisnis dibidang peternakan di peternak rakyat (Herman et al. 2018). Kegiatan beternak yang telah mengarah pada orientasi bisnis mampu menjadi modal awal dibangunnya sebuah industri peternakan rakyat. Sekolah Peternakan Rakyat (SPR) merupakan sebuah gagasan yang dibentuk dengan tujuan mengubah pola pikir peternak untuk bersama-sama membangun bisnis kolektif berjamaah sehingga IPTEK untuk perbaikan produktivitas ternak dapat dengan mudah masuk dan diaplikasikan. Adanya peran pemerintah daerah dan penguatan ilmu pengetahuan dari pihak kampus diharapkan mampu membangun peternakan rakyat berbasis kelompok yang mandiri dan kuat sehingga produktivitas ternak dapat dengan mudah ditingkatkan dan peternak dapat mencapai kesejahteraan.

SPR Maju Bersama adalah SPR yang dibentuk melalui kerjasama antara Lembaga Penelitian dan Pengabdian Masyarakat (LPPM) Institut Pertanian Bogor (IPB) dengan Pemerintah Kabupaten Musi Banyuasin sejak tahun 2013 dan dinyatakan lulus pada tahun 2017. SPR yang telah dinyatakan lulus kemudian membentuk koperasi sebagai wadah untuk pengembangan bisnis kolektif serta Stasiun Lapang (SL-SPR) yang digunakan sebagai unit riset bagi perguruan tinggi. SPR Maju Bersama berada di Kecamatan Sungai Lilin dimana sebagian besar wilayahnya berupa lahan sawit dan karet dengan luas masing-masing 2.957 dan 6.532 (BPS 2018).

Sapi Bali merupakan jenis sapi yang dipelihara di SL-SPR Maju Bersama. Sapi Bali memiliki nilai ekonomis yang tinggi dan paling banyak dipelihara oleh peternak kecil karena memiliki tingkat kesuburan yang tinggi, kematian yang rendah, mudah beradaptasi dengan lingkungan serta mempunyai persentasi karkas yang tinggi (Purwantara et al. 2012). Tingginya tingkat fertilitas pada sapi Bali dalam menghasilkan pedet, merupakan salah satu potensi yang mampu mendukung upaya peningkatan populasi melalui usaha pembiakan. Performa reproduksi induk merupakan salah satu faktor terpenting yang perlu diketahui dalam menjunjang efisiensi program pembiakan sapi potong. Beberapa parameter performa reproduksi yang penting meliputi umur pertama beranak, tingkat kelahiran (calving rate), jarak beranak (calving interval), service per conception (S/C), serta masa kosong (days open) (Rahayu 2015).

Ketersediaan populasi sapi Bali yang cukup besar di SPR Maju Bersama didukung dengan potensi sumber daya alam di wilayah Kecamatan Sungai Lilin dan diperkuat dengan peternak yang telah terkonsolidasi, merupakan modal awal dalam membangun usaha pembiakan sehingga dapat diperoleh ternak yang berkualitas dan mampu meningkatkan kesejahteraan peternak. Penelitian ini bertujuan untuk melihat potensi dan performa reproduksi indukan sapi Bali di SL-SPR Maju Bersama sebagai baseline untuk membangun industri pembiakan sapi potong di peternak rakyat.

\section{MATERI DAN METODE}

Penelitian dilakukan di SL-SPR Maju Bersama pada bulan Agustus-Desember 2019. Materi yang digunakan dalam penelitian ini adalah induk sapi Bali sejumlah 330 ekor milik 247 peternak dengan kriteria umur 3-10 tahun. Performa reproduksi yang diamati meliputi umur pertama beranak, calving interval, days open, $\mathrm{S} / \mathrm{C}$ dan BCS.

\section{Koleksi Data}

Teknik pengumpulan data dilakukan melalui wawancara dan pengamatan langsung untuk memperoleh data primer. Wawancara dilakukan pada pemilik ternak dengan menggunakan kuisioner sesuai daftar pertanyaan yang telah disusun sebelumnya, sedangkan pengamatan langsung dilakukan pada indukan sapi Bali. Responden ditentukan dengan metode sensus. Metode sensus memungkinkan untuk menggali informasi secara rinci dan mendalam terkait semua unit populasi sehingga dapat menghasilkan data statistik yang berkualitas (Taguchi 2018).

\section{Analisis Performa Reproduksi Sapi Bali}

Umur pertama beranak diperoleh dengan wawancara pemilik ternak dan inseminator. Calving interval atau jarak beranak diperoleh dengan menghitung selisih tanggal dua kelahiran berturut-turut (beranak pertama dan kedua, dan seterusnya) (Titterington et al. 2017)and investigate the effects of breed, season, year and progeny gender on CI. The CI data included 273764 records collected between 1997 and 2012 and included the seven most common breeds (and their crosses. Days open atau masa kosong diperoleh dengan menghitung selisih jarak waktu antara sapi beranak sampai dengan perkawinan yang menghasilkan kebuntingan (Ball dan Peters 2007). Service per conception (S/C) dihitung dengan membagi jumlah perkawinan pada sekelompok ternak dengan jumlah induk yang bunting (Suhendro et al. 2013).

Body condition score (BCS) merupakan metode yang digunakan untuk menilai tingkat kegemukan ternak yang dilakukan dengan teknik pengamatan dan perabaan. Pengukuran BCS dilakukan dengan pengamatan dan perabaan tulang pinggul dan tulang rusuk menggunakan metode Soares dan Dryden (2011)body length, hip and shoulder heights, heart girth, and metatarsal length were measured on 100 one to two years old Bali (Bos javanicus pada sapi Bali dengan skala 1-5 (1= tulang sangat menonjol; $2=$ tulang terlihat; $3=$ tulang terlihat namun tertutupi jaringan lunak; $4=$ tulang hanya nampak jika diraba; $5=$ tulang tidak terlihat). 


\section{Analisis Data}

Data dianalisis dengan analisis statistik dekriptif dengan menggunakan software Minitab 17 untuk menghitung rataan dan standar error performa reproduksi berupa umur pertama beranak, CI, DO dan S/C. Analisis deskriptif digunakan untuk menginterpretasikan objek sesuai dengan data yang diperoleh (Steel dan Torrie 1993). Hasil olah data disajikan secara deskriptif dengan metode campuran, yaitu kombinasi pendekatan kualitataif dan kuantitatif untuk mendapatkan fakta dan pemahaman yang komprehensif (Taguchi 2018).

\section{HASIL DAN PEMBAHASAN}

\section{Profil SL-SPR Maju Bersama}

Wilayah SL-SPR Maju Bersama mencakup 12 Desa dari 15 Desa yang ada di Kecamatan Sungai Lilin, antara lain Desa Pinang Banjar, Sri Gunung, Sumber Rejeki, Linggo Sari, Mulyo Rejo, Sukadamai Baru, Nusa Serasan, Cinta Damai, Berlian Makmur, Bukit Jaya, Bumi Kencana dan Panca Tunggal. Peternak yang tergabung dalam SL-SPR Maju Bersama berjumlah 333 orang dengan total populasi sapi potong sebanyak 1443 ekor. Rata-rata kepemilikan sapi potong tiap peternak di SL-SPR Maju Bersama adalah 4,42 $\pm \mathbf{0 , 9 5}$ ekor. Irianto et al. (2020) menyatakan bahwa skala kepemilikan ternak dikelompokkan menjadi 3 bagian, yaitu skala kecil (1-5 ekor), skala menengah (6-10 ekor) dan skala besar ( $>10$ ekor). Kondisi ini menunjukkan bahwa kepemilikan ternak yang ada di SL-SPR Maju Bersama masih tergolong skala kecil.

Populasi sapi potong di SL-SPR Maju Bersama didominasi oleh sapi Bali sebanyak $80 \%$. Struktur populasi sapi Bali (Tabel 1) menunjukkan bahwa persentase betina

Tabel 1. Struktur populasi dan komposisi sapi bali di SL-SPR

\begin{tabular}{lccc}
\hline Komposisi ternak & \multicolumn{3}{c}{ Jumlah (total) } \\
\cline { 2 - 4 } & Ekor & UT & $\%$ \\
\hline Dewasa & & & \\
Jantan & 80 & 80 & 6.3 \\
Betina & 402 & 402 & 31.5 \\
Jumlah & 482 & 482 & 37.7 \\
Muda & & & \\
Jantan & 193 & 115.8 & 15.1 \\
Betina & 260 & 156 & 20.4 \\
Jumlah & 453 & 271.8 & 35.5 \\
Pedet & & & \\
Jantan & 177 & 44.25 & 13.9 \\
Betina & 165 & 41.25 & 12.9 \\
Jumlah & 342 & 85.5 & 26.8 \\
Total jantan & 450 & 240.05 & 35.2 \\
Total betina & 827 & 599.25 & 64.8 \\
\hline Jumlah (total) & 1277 & 839.3 & 100 \\
\hline Keterangan: UT= Unit Ternak Dewasa: 1 UT, Muda: 0,6 UT, \\
Pedet: 0,25 UT. Umur dewasa: $>24$ bulan atau sudah kawin dan \\
beranak, Umur muda: 11-24 bulan, Umur pedet: 0-10 bulan
\end{tabular}

dewasa yang paling tinggi, yaitu sebesar 31,5\% dari total populasi. Proporsi betina dewasa yang jauh lebih banyak dibanding jantan dewasa dikarenakan umumnya sapi jantan di SL-SPR yang telah memasuki umur dewasa (2 tahun) dikeluarkan untuk dijual. Tingginya proporsi betina dewasa dalam satu populasi sangat mendukung program pembiakan di peternakan rakyat (Afriani et al. 2019). Proporsi betina yang lebih banyak dibandingkan jantan juga terlihat pada kelompok umur muda. Hal ini dikarenakan sebagian peternak juga menjual sapi jantan pada umur lepas sapih. Sejalan dengan penelitian (Kusuma et al. 2017) bahwa peternak tradisional cenderung mempertahankan betina muda untuk dipersiapankan sebagai replacement stock induk dan hanya sebagian kecil yang tetap memelihara jantan muda untuk dijadikan pejantan. Proporsi sapi jantan lebih banyak dibandingkan betina pada kategori pedet disebabkan angka kelahiran jantan yang lebih besar dibandingkan betina. Kondisi tersebut menunjukkan bahwa kegiatan beternak di SL-SPR Maju Bersama masih didominasi oleh usaha pembiakan dimana indukan memiliki jumlah lebih banyak dan cenderung dipertahankan untuk menghasilkan anak.

\section{Potensi pakan dan kapasitas sapi potong di SL-SPR Maju Bersama}

Ketersediaan pakan berbasis sumberdaya alam lokal merupakan faktor penting dalam menunjang usaha peternakan yang berkelanjutan. Wilayah SL-SPR berada di Kecamatan Sungai Lilin dengan potensi lahan perkebunan yang luas berupa lahan sawit dan karet dengan luas masingmasing 2.957 dan 6.532 Hektar (BPS 2019). Total potensi pakan yang diperoleh dari produksi hijauan dan sisa tanaman pertanian di SL-SPR sebanyak 15.646,92 Ton BK/ tahun (Tabel 2).

Produksi pakan dapat digunakan untuk mencukupi kebutuhan sapi potong dengan kapasitas tampung sebanyak13.725 ST, sehingga wilayah SL-SPR dapat

Tabel 2. Produksi pakan, kapasitas tampung dan kapasitas penambahan sapi di SL-SPR

\begin{tabular}{lcccc}
\hline Desa & TPP & PTSP & KT & KPPTR \\
\hline Pinang Banjar & 972,23 & 103,9 & 853 & 749 \\
Sumber Rejeki & 885,05 & 99,2 & 776 & 677 \\
Linggo sari & 569,25 & 49,2 & 499 & 450 \\
Mulyo Rejo & 946,41 & 78,7 & 830 & 751 \\
Sukadamai Baru & $1.073,72$ & 27,8 & 942 & 914 \\
Nusa Serasan & $1.009,81$ & 69,7 & 886 & 816 \\
Cinta Damai & $1.127,82$ & 262,1 & 989 & 727 \\
Berlian Makmur & $1.353,23$ & 18,3 & 1.187 & 1.169 \\
Bukit Jaya & $1.059,96$ & 53,6 & 930 & 876 \\
Bumi Kencana & $1.778,59$ & 139,5 & 1.56 & 1.421 \\
Panca Tunggal & 940,34 & 71,9 & 825 & 753 \\
Sri Gunung & $3.930,51$ & 37,2 & 3.448 & 3.411 \\
\hline Total & $15.646,92$ & $1.010,75$ & 13.725 & 12.715 \\
\hline Keternan; TPP & &
\end{tabular}

Keterangan; $\mathrm{TPP}=$ total produksi pakan (ton $\mathrm{BK} /$ Tahun); $\mathrm{PTSP}=$ populasi ternak sapi potong (ST); KT= kapasitas tampung (ST); $\mathrm{KPPT}=$ kapasitas peningkatan populasi ternak ruminansia (ST) 
melakukan peningkatan populasi sebanyak 12.715 ST (Tabel 2). Potensi ini merupakan peluang yang cukup besar untuk dilakukan pengembangan usaha pembiakan sapi Bali. Selain itu, pemanfaatan pakan lokal dengan sistem integrasi ternak dan tanaman juga dapat digunakan sebagai upaya untuk peningkatan produktivitas ternak (Salendua et al. 2018).

\section{Performa Reproduksi Sapi Bali}

\section{Umur pertama beranak}

Rata-rata umur pertama beranak induk sapi Bali di SL-SPR diperoleh sebesar 1098 \pm 12.0 hari (Tabel 3). Hasil ini lebih kecil dibandingkan penelitian Siswanto et al. (2013) pada sapi Bali di peternak rakyat yaitu sebesar 1104 hari, dan lebih besar dibandingkan penelitian Samberi et al. (2010) sebesar 31,92 $\pm 0,19$ bulan. Penelitian Gunawan et al. (2011) menyebutkan bahwa sapi Bali yang dipelihara di Pusat Pembibitan Sapi Bali memiliki umur pertama beranak yang lebih besar yaitu 43,86 bulan. Umur pertama beranak sangat dipengaruhi oleh umur pubertas dan umur pertama kali dikawinkan. Semakin cepat ternak dikawinkan maka semakin cepat pula ternak bereproduksi sehingga usaha pembiakan ternak semakin ekonomis. Mukasa-Mugerwa (1989) menyatakan bahwa umur pertama beranak yang lebih cepat mampu meningkatkan produktivitas sapi dalam satu periode masa hidupnya. Keterlambatan beranak disebabkan oleh pengelolaan ternak, kesuburan serta kesehatan ternak (Zavadilova 2013).

Tabel 3. Rata-rata dan standar eror (SE) performa reproduksi induk sapi Bali di SL-SPR

\begin{tabular}{lc}
\hline Performa reproduksi & Rata-rata \pm SE \\
\hline Umur pertama beranak (hari) & $1098 \pm 12$. \\
Calving interval (hari) & $457.25 \pm 8.57$ \\
Days open (hari) & $109.25 \pm 8.57$ \\
S/C & $5.463 \pm 0.42$ \\
\hline
\end{tabular}

\section{Calving interval (CI)}

CI sapi Bali di SL-SPR diperoleh sebesar 457.25 \pm 8.57 hari (Tabel 3). Hasil ini lebih panjang dari Samberi et al. (2010) sebesar 31,92 $\pm 0,19$ bulan. Sedangkan pada penelitian Gunawan et al. (2011) menunjukkan CI sapi Bali di Pusat Pembibitan Sapi Bali sebesar 360,93 $\pm 4,47$ hari. Calving interval adalah jarak waktu antara satu kelahiran dengan kelahiran berikutnya. CI penting untuk diketahui karena keteraturan jarak beranak yang dihasilkan pada tiap individu menunjukkan kesinambungan dalam menghasilkan anak dalam satu periode masa hidupnya (Fauziah et al. 2015). Faktor yang mempengaruhi nilai CI antara lain adalah lama bunting dan masa kosong pada ternak. Silva et al. (1992) menyatakan bahwa CI pada sapi muda cenderung panjang karena umumnya induk muda memiliki tingkat stress yang lebih tinggi dibandingkan induk yang lebih tua khususnya pada saat laktasi.

\section{Days open (DO)}

Days open atau masa kosong indukan sapi Bali di SL-SPR diperoleh $109.25 \pm 8.57$ hari. DO pada penelitian ini lebih pendek dibanding penelitian Supriantono et al. (2008) terhadap sapi Bali yang juga dipelihara dipeternak rakyat yaitu sebesar 130,24 \pm 24 hari. Penelitian Akriono et al. (2017) pada sapi PO miliki nilai DO 107,34 $\pm 32,38$, sedangkan pada sapi Peranakan Limousin 130,30 $\pm 43,78$. Semakin panjang nilai DO menunjukkan bahwa efisiensi reproduksi induk yang semakin rendah. DO sangat dipengaruhi oleh lamanya penyapihan pedet, dimana semakin lama pedet disapi maka akan menyebabkan mundurnya perkawinan kembali setelah beranak. Rata-rata peternak di SL-SPR menyapih pedet pada usia 3 bulan. Ketidak tepatan deteksi birahi pada ternak setelah beranak juga menyebabkan DO semakin panjang. Dalam membangun usaha pembiakan agar efisien dan induk dapat beranak setiap tahun, maka induk maksimal memiliki nilai DO maksimal 3 bulan.

\section{Service per conception $(\mathrm{S} / \mathrm{C})$}

Nilai S/C indukan sapi Bali di SL-SPR diperoleh $5.463 \pm 0.42$ kali (Tabel 3). Nilai ini lebih tinggi apabila dibandingkan dengan penelitian Samberi et al. (2010) pada sapi Bali yaitu sebesar 1,49 $\pm 0,9$ kali dan Siswanto et al. (2013) 1,6 kali. Keterbatasan data yang ada di inseminator serta catatan peternak, sehingga nilai $\mathrm{S} / \mathrm{C}$ diperoleh dengan cara menghitung days open dibagi dengan masa birahi dengan asumsi setiap birahi, sapi dikawinakan. Tingginya nilai S/C pada indukan di SL-SPR disebabkan karena keterlambatan mengawinkan ternak sehingga terlewat masa birahi. Keterlambatan ini disebabkan kurangnya perhatian peternak dalam deteksi birahi serta terbatasnya inseminator yang ada diwilayah setempat. Semakin tinggi nilai S/C maka akan memperpanjang jarak beranak sehingga akan menambah biaya dan tenaga untuk pemberian pakan. Hal ini tentunya kurang efisien untuk usaha pembiakan sehingga perlu dilakukan perbaikan manajemen perkawinan dari peternak.

\section{Body condition score (BCS)}

Rata-rata induk sapi Bali di SL-SPR memiliki nilai BCS 3 dengan persentase tertingi yaitu 43\% (Tabel 4). Nilai BCS 3 diartikan bahwa nampak 2 tulang rusuk yang terlihat diperut atau dapat diklasifikasikan sebagai kategori sedang. Bagiarta et al. (2017) menyatakan bahwa nilai BCS ternak tergatung dari tujuan pemeliharaan, dimana untuk ternak yang dipelihara dengan tujuan penggemukan, semakin besar nilai BCS maka semakin baik, sedangkan untuk tujuan pembibitan atau pembiakan yang menghasilkan pedet, maka paling baik adalah BCS 3 .

Tabel 4. BCS induk sapi Bali di SL-SPR

\begin{tabular}{lcc}
\hline BCS & Jumlah (ekor) & Persentase (\%) \\
\hline 1 & 11 & 3 \\
2 & 118 & 29 \\
3 & 173 & 43 \\
4 & 93 & 23 \\
5 & 7 & 2 \\
\hline Total & 402 & 100 \\
\hline Sumber: Data Primer yang telah diolah 2019
\end{tabular}




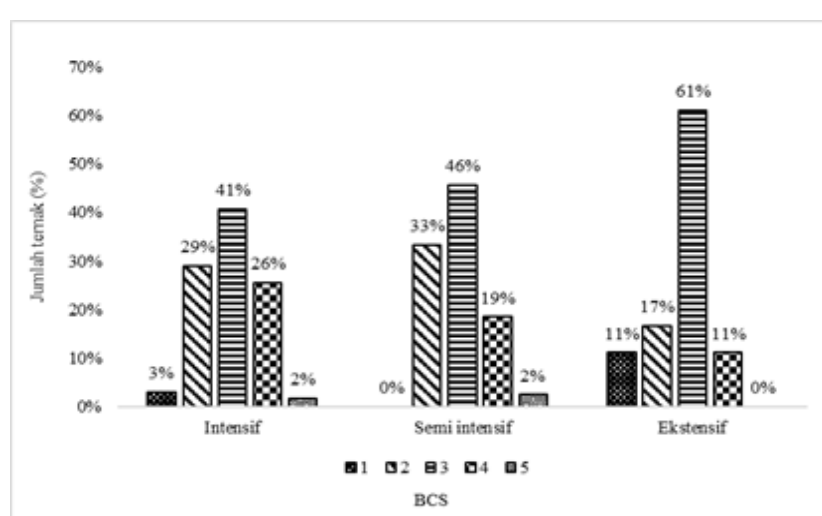

Gambar 1. Nilai BCS berdasarkan sistem pemeliharaan intensif, semi intensif dan esktensif di SL-SPR Maju Bersama

BCS merupakan salah satu aspek yang penting diketahui agar manajemen usaha pembiakan sapi potong berjalan efisien. Sapi dengan skor tubuh yang terlalu kurus rentan terhadap masalah kesehatan, sedangkan pada ternak yang terlalu gemuk membutuhkan biaya dan tenaga lebih untuk pemeliharaan serta rawan terjadi distokia karena lemak berlebihan pada daerah panggul.

Sistem pemeliharaan indukan sapi Bali baik secara intensif, semi intensif dan ekstensif, rata-rata memiliki nilai BCS 3 (Gambar 1). Induk sapi Bali yang dipelihara pada sistem intensif memiliki nilai BCS dalam semua kategori, yaitu 1 sampai 5. Pada sistem pemeliharaan secara ekstensif, persentase nilai BCS 3 paling tinggi dibandingkan kategori lain $(61 \%)$, namun memiliki nilai BCS 1 yang paling tinggi pula (11\%) diantara sistem pemeliharaan lainnya serta tidak memiliki indukan dengan nilai BCS 5. Sedangkan untuk sistem semi intensif, tidak terdapat indukan yang memiliki nilai BCS 1.

\section{KESIMPULAN}

Pembiakan indukan sapi Bali yang ada di SLSPR memiliki potensi yang cukup. Performa reproduksi berupa umur pertama beranak, calving interval dan days open sudah cukup baik dan berada pada kategori normal, namun perlu dilakukan perbaikan sistem perkawinan untuk mengurangi nilai S/C. Potensi pakan, indeks daya dukung dan kapasitas tampung tergolong dalam kategori aman sehingga menunjang perbanyakan populasi. Baseline data yang diperoleh dapat digunakan untuk memulai usaha pembiakan dalam rangka pengembangan populasi dan peningkatan mutu genetik ternak sapi Bali.

\section{UCAPAN TERIMA KASIH}

Ucapan terima kasih kepada Kementerian Riset dan Teknologi yang telah memberikan dana hibah untuk penelitian melalui Program Magister Menuju Doktor untuk Sarjana Unggul (PMDSU).

\section{DAFTAR PUSTAKA}

Afriani, T., M. P. Agusta, Yurnalis, F. Arlina, \& D. E. Putra. 2019. Estimasi dinamika populasi dan pembibitan sapi potong di Kecamatan Bayang Kabupaten Pesisir Selatan. J. Peternakan Indonesia. 21(2):130-142.

Akriono, M. L., S. Wahjuningsih, \& M. N. Ihsan. 2017. Performans reproduksi Sapi Peranakan Ongole dan Peranakan Limousin di Kecamatan Padang Kabupaten Lumajang. J. Trop. Anim. Prod. 18(1):77-81.

Bagiarta I. W., I. M. Mudita, G. K. Roni, \& S. A. Lindawati. 2017. Dimensi tubuh sapi Bali di Unit Pelaksana Teknis Pembibitan sapi Bali Sobangan. Peternakan Tropika. 5(1):181-188.

Ball, P. J. H., \& A. R. Peters. 2007. Reproduction in Cattle. 3rd Edition. Blackwell Publishing, USA.

Budiawan, A., M. N. Ihsan, S. Wahjuningsih. 2015. Hubungan body condition score terhadap service per conception dan calving interval sapi potong Peranakan Ongole di Kecamatan Babat Kabupaten Lamongan. J. Ternak Trop. 16(1):34-40.

Fauziah,L.W., W. Busono, \& G. Ciptadi. 2015. Performans reproduksi sapi Peranakan Ongole dan Peranakan Limousin pada paritas berbeda di Kecamatan Paciran Kabupaten Lamongan. J. Ternak Trop. 16(2):49-54.

Gunawan, A., R. Sari, Y. Parwoto, \& M. J. Uddin. 2011. Non genetic factors effect on reproductive performance and preweaning mortality from artificially and naturally bred in Bali cattle. J. Indonesian. Trop. Anim. Agric. 36(2):83-90.

Hakim, L., G. Ciptadi, \& V. M. A. Nurgiartiningsih. 2010. Model rekording data performans sapi potong lokal di Indonesia. J. Ternak Trop. 11(2):61-73.

Herman, H., F. Madarisa, \& Syahrial. 2018. Pengembangan usaha sapi potong Kelompok Tani Ternak Hidayah Kampung Laban Kenagarian Salido Kabupaten Pesisir Selatan. J. Bisnis Tani. 4(1):61-76.

Irianto, A., A. Gunawan, \& Muladno. 2020. Perbaikan mutu genetik melalui sistem grading ternak dalam upaya menunjang program pemuliaan berbasis digital. J. Ilmu dan Teknologi Peternaan. Trop. 7(1):35-41.

Kusuma, S. B., N. Ngadiyono, \& Sumadi. 2017. Estimasi dinamika populasi dan penampilan reproduksi Sapi Peranakan Ongole Di Kabupaten Kebumen Provinsi Jawa Tengah. Bul. Peternak. 41(3):230-242.

Mauludin, M. A, S. Winaryanto, \& S. Alim. 2012. Peran kelompok dalam mengembangkan keberdayaan peternak sapi potong (kasus di wilayah Selatan Kabupaten Tasikmalaya). J. Ilmu Ternak. 12(1):1-8.

Purwantara, B., R. R. Noor, G. Andersson, \& H. Rodriguez-Martinez. 2012. Banteng and Bali cattle in Indonesia: Status and forecasts. Reprod. Domest. Anim. 47(suppl.1):2-6.

Rahayu, S. 2015. The reproductive performance of Bali cattle and it's genetic variation. J. Bio. Res. 20(1):2835.

Salendua, A. H. S., F. H. Elly, R. E. M. F. Osak, \& I. D. R. Lumenta. 2018. Cattle farm development by forages 
cultivation on coconut land based on carrying capacity in West Bolangitang, Indonesia. Int. J. Environ. Agric. Biotech. 3(3):1139-1144.

Samberi, K., N. Ngadiyono, \& Sumadi. 2010. Estimasi dinamika populasi dan produktivitas sapi Bali di Kabupaten Kepulauan Yapen, Propinsi Papua. Buletin Peternakan. 34(3):169-177.

Silva, H. M., C. J. Wilcox, W. W. Thatcher, R. B. Becker, \& D. Morse. 1992. Factors affecting days open, gestation length, and calving interval in Florida dairy cattle. J. Dairy Sci. 75(1):288-293.

Siswanto, M., N. W. Patmawati, N. N. Trinayani, I. N. Wandia, \& I. K. Puja. 2013. Penampilan reproduksi sapi Bali pada peternakan intensif di Instalasi Pembibitan Pulukan. J. Ilmu dan Kesehatan Hewan. 1(1):11-15.

Soares, F. S., \& G. M. L. Dryden. 2011. A body condition scoring system for Bali cattle. Asian-Australasian J. Anim. Sci. 24(11):1587-1594.
Sodiq, A, \& N. Hidayat. 2014. Kinerja dan perbaikan sistim produksi peternakan sapi potong berbasis kelompok di pedesaan. J. Agripet. 14(1):56-64.

Steel, R. G. D., \& J. H. Torrie. 1993. Prinsip dan prosedur statistika: studi pendekatan biometrik. Gramedia Pustaka, Jakarta.

Suhendro, D., G. Ciptadi, \& Suyadi. 2013. Reproductive performance of Swamp Buffalo (Bubalus Bubalis ) in Malang Regency. J. Ternak Trop. 14(1):1-7.

Supriantono, A., L. Hakim, Suyadi, \& Ismudiono. 2008. Performansi sapi bali pada tiga daerah di Provinsi Bali. Berk. Penel. Hayati. 13(2):147-152.

Taguchi, N. 2018. Description and explanation of pragmatic development: Quantitative, qualitative, and mixed methods research. System. 30(1):23-32.

Titterington, F. M., F. O. Lively, S. Dawson, A. W. Gordon, \& S. J. Morrison. 2017. The effects of breed, month of parturition and sex of progeny on beef cow fertility using calving interval as a measure. Adv. Anim. Biosci. 8(1):67-71. 